\title{
A biblioteca escolar e a leitura do texto literário infanto-juvenil: informação para a educação e o lazer
}

The school library and the reading of infant-juvenile literary text: information for education and leisure

\author{
João Batista Ernesto de Moraes (1) e Roberta Caroline Vesú Alves (2)
}

(1) Faculdade de Filosofia e Ciências - Unesp, - Av. Higyno Muzzi Filho, 737, Marília - São Paulo Brasil - CEP: 17525-900, joaoernesto@pq.cnpq.br (2) robertavesu@gmail.com

\begin{abstract}
Resumen
Las bibliotecas escolares poseen las responsabilidades de atender diferentes necesidades de información, difundir la lectura e incentivar su costumbre. Pero, ¿como justificar todo el esfuerzo en proporcionar el acceso al contenido de los textos literarios infanto-juveniles? Ante eso, el objetivo ha sido analizar los subsidios teóricos que abordan la importancia de la lectura y del texto literario infanto-juvenil, visando también verificar la importancia del conocimiento de los temas de eses textos direccionados a los usuarios adolescentes. La metodología usada constituyese en estudio exploratorio interdisciplinario, buscando informaciones en diferentes áreas del conocimiento para fundamentar esta investigación. Como resultado, ha sido verificado que la literatura infantojuvenil, direccionada al público adolescente, posee valerosas informaciones para el desarrollo educacional adolescente, al mismo tiempo que propicia el ocio.
\end{abstract}

Palabras-clave: Bibliotecas escolares. Lectura. Texto literario infanto-juvenil. Usuario adolescente. Información para la educación. Información para la promoción de la diversión. Necesidades de información. Incentivo a la lectura.

\section{Introdução}

As bibliotecas escolares possuem responsabilidades que impelem o profissional bibliotecário a descobrir os materiais que correspondam às demandas de informação voltadas à educação e ao lazer, contribuindo para garantir o uso de diversos tipos de obras em diferentes suportes informacionais.

Além disso, há a preocupação em incentivar a leitura de ficção de acordo com os gostos ou interesses dos usuários.

No entanto, existe certa dificuldade em atender às solicitações dos usuários sobre os textos literários infanto-juvenis, pois, os temas desse tipo de texto muitas vezes não estão explícitos, necessitando de análise para identificação de

\begin{abstract}
School libraries take responsibilities for attending different information needs, propagating reading and stimulating this costum. But, how to justify all the effort to provide the access to content of infantjuvenile literary texts, and which are the benefits of reading and literature to individuals in a school environment? In front of this, it has been aimed to analyse theoretical subsidies approaching reading and importance of infant-juvenile literary text, in the context of school library, seeking also examine knowledge importance of these texts themes directed to adolescents users. The used methodology constitutes an interdisciplinary exploring study looking for informations in different areas of knowledge to establish this research. As result, it's found that infant-juvenile literature has valuable informations for the educacional development, at the same time that promotes leisure.

Keywords: School library. Reading. Infant-juvenile literary text. Adolescent user. Information for education. Information for promotion of leisure. Information needs. Incentive to reading
\end{abstract}

conteúdo e posteriormente representação em sistema de recuperação de informação para permitir o acesso à obra. Mas, como justificar todo o esforço em proporcionar o acesso ao conteúdo dos textos literários infanto-juvenis, e quais os benefícios da leitura e da literatura para os indivíduos no ambiente escolar?

Diante dessas questões, objetivou-se analisar os subsídios teóricos que abordam a importância da leitura e do texto literário infanto-juvenil, no contexto da biblioteca escolar, visando também verificar a importância do conhecimento dos temas desses textos voltados aos usuários adolescentes. A metodologia utilizada constituise em estudo exploratório interdisciplinar, procurando informações em diferentes áreas do conhecimento para fundamentar esta pesquisa em Ciência da Informação. 


\section{Leitura e texto literário infanto-juvenil no contexto da biblioteca escolar}

Os estudantes necessitam de diversos tipos de materiais de informação (tangíveis ou intangíveis), que irão garantir seu desenvolvimento educacional, como também, é importante que conheçam diferentes tipos de textos (verbais ou não verbais, dissertativos ou narrativos, por exemplo) para compreenderem os meios de expressão utilizados pelo ser humano.

Para Macedo (2005) aos alunos ou educandos cabe o direito de receber formação adequada para se tornarem leitores efetivos, capazes de produzir texto coerente, serem pensadores críticos e se transformarem em usuários da informação. Também, devem ser preparados para se tornem futuros agentes sociais, concorrendo para o desenvolvimento do país no âmbito econômico, social e cultural.

Diante disso, verifica-se a contribuição da literatura de ficção, pois, tem a função social de fazer o leitor perceber a realidade que o cerca (Caldin, 2003), além de ter a função educativa, exprimindo o comportamento do ser humano (Magnani, 2001).

Nesse contexto, a leitura possibilita a aprendizagem, associação, interpretação, entre outros fatores, que colaboram para a reelaboração de novas mensagens, constituindo em elemento que possibilita e transforma novas descobertas (Scheffer, 2002).

Além disso, a leitura do texto de ficção, apesar de veicular temas reais importantes, é vista como atividade de entretenimento ou lazer, segundo Dumont (2000), levando a liberação do espírito que transcende para outro contexto (escape ou fuga agradável).

De acordo com Souza (2006, p. 53-54),

A literatura infanto-juvenil é a primeira forma escrita de contato da criança e do jovem com as tradições culturais e literárias de seu povo. Ao mesmo tempo que promove recreação, também cultiva valores necessários à vida em sociedade e favorece o raciocínio e a inteligência da criança e do jovem. Ela pode significar também uma evasão, se os elementos da fantasia e da imaginação estiverem presentes. Sua função primeira é despertar, na criança e no jovem, o gosto pela leitura e permitirIhes um contato com a realidade que os cerca. Seja prosa de ficção, poesia ou teatro, suas histórias abrangem aventuras sublimes, trágicas, pitorescas, patéticas, de mistério, de ficção científica etc.

Diante da diversidade em que se apresenta o texto literário infanto-juvenil, esta pesquisa delimita-se em abordar o texto narrativo longo, em prosa, voltado ao público adolescente, o qual possui as seguintes características:

- a extensão da narrativa em prosa, geralmente, é longa, as ilustrações são em preto ou não apresenta imagens (Guedes, 2001);

- tem a função educativa, para a criança e o adolescente, do gosto e de identificação, permitindo seu avançar no processo de amadurecimento (Magnani, 2001);

- escrito por autores contemporâneos, contribui para desenvolver o conhecimento sobre temas de fatos reais (culturais, sociais, históricos, biológicos, psicológicos etc.) e sobre as expressões da linguagem (relação com a arte e a estética), segundo Souza (2006).

Pode-se verificar também que os personagens principais são adolescentes (heróis), envolvidos em histórias que se referem às temáticas próprias do período da adolescência, buscando a superação de obstáculos e problemas, e mostrando amadurecimento no final da história.

Essas características ajudam a agregar informações ao texto literário que podem estar relacionadas com o desenvolvimento educacional dos leitores, ao mesmo tempo em que promove o lazer. A temática veiculada por meio da literatura infanto-juvenil é muito importante, pois, se refere aos temas, muitas vezes conflituosos, que são vivenciados por muitos adolescentes na vida real. Portanto, esse tipo de leitura deve ser incentivado, como também, deve-se garantir o acesso a esse tipo de informação.

\section{Identificação de temas para acesso a leitura}

Para que o leitor encontre a leitura correspondente ao seu gosto ou interesse, é preciso oferecer a ponte entre eles, atendendo as necessidades de informação. Isso pode ocorrer por meio do bibliotecário e no âmbito dos sistemas de recuperação da informação, que visam propiciar o acesso ao conteúdo dos documentos. Um exemplo desses sistemas pode ser o catálogo (Dias; Naves, 2007).

Mas, para que isso seja concretizado, há a necessidade de se conhecer o conteúdo desses textos, utilizando uma análise documental de conteúdo própria ao texto narrativo de ficção.

A análise documental de conteúdo, segundo Pinto Molina (1993), compreende os procedimentos que expressam o conteúdo dos documentos (análise, condensação e representação) para fins de recuperação da informação. 
Para a análise documental de texto literário destaca-se a contribuição do Percurso Gerativo de Sentido, utilizado como estratégia para a compreensão da estrutura e identificação de temas. Essa teoria origina-se da Semiótica francesa de Greimas $(1971,1975)$, que tem pesquisadores, lingüistas, como Tatit (2003) e Fiorin (1999, 2008) no Brasil.

O Percurso Gerativo de Sentido consiste em um "[...] um simulacro metodológico, para explicar o processo de entendimento, em que o leitor precisa fazer abstrações, a partir da superfície do texto, para poder entendê-lo" (Fiorin, 1999). Compreende as estruturas profunda ou fundamental (categorias semânticas), narrativa (estrutura canônica: manipulação, competência, performance e sanção pragmática e cognitiva) e discursiva (concretização de temas e figuras). Cada estrutura ou nível do percurso possui uma sintaxe e uma semântica (Fiorin 2008; Greimas, 1971, 1975; Tatit, 2003).

Observa-se em Damazo (2006) e Lara (2007), que as fases de manipulação e sanção da estrutura narrativa concentram os temas mais relevantes. Além disso, para a análise de assunto do texto de ficção devem ser considerados os percursos temático e figurativo, que permitem a abstração aos temas de estrutura profunda (Moraes; Guimarães, 2006; Moraes; Guimarães; Guarido, 2007).

Vale ressaltar aqui que tema principal, identificado no texto literário infanto-juvenil, corresponde ao tema de nível profundo do Percurso Gerativo de Sentido, que também pode corresponder ao que Kobashi (1994) determina como tema: idéia principal discutida ou tratada no texto. Assim sendo, reserva-se a denominação de tema ao resultado do entendimento do encadeamento de figuras e temas em nível discursivo do referido percurso (Alves, 2008).

A identificação desses temas ocorre em níveis, e para exemplificar esses níveis apresentam-se os temas de três textos literários analisados por Alves (2008).

Texto literário "O grande desafio" de Pedro Bandeira (1997):

- Tema principal (nível profundo): Incapacidade do deficiente visual versus Capacidade do deficiente visual.

- Temas de nível narrativo e discursivo: manipulação (dúvida); sanção pragmática (prisão); amor); sanção cognitiva (herói).

- Temas gerais de nível discursivo: deficiente visual; tecnologia para o deficiente visual.
Texto literário "Diário de Raquel" de Marcos Rey (2006):

- Tema principal (nível profundo): assédio sexual em garota de rua versus Repúdio ao assédio sexual em garota de rua.

- Temas de nível narrativo e discursivo: manipulação: assédio sexual; sanção pragmática (morte; felicidade).

- Temas gerais de nível discursivo: drogas; roubo; garota de rua; assédio sexual; pobreza; sonho.

Texto literário "Depois daquela viagem: diário de bordo de uma jovem que aprendeu a viver com AIDS" de Valéria Piassa Polizzi:

- Tema principal 1 (nível profundo): Relação sexual desprotegida versus Relação sexual segura.

- Tema principal 2 (nível profundo): Discriminação ao portador do vírus da AIDS versus Indiscriminação ao portador do vírus da AIDS.

- Temas de nível narrativo e discursivo: manipulação 1 (relação sexual desprotegida); sanção pragmática 1 (AIDS); manipulação 2 (discriminação ao portador do vírus da AIDS); sanção cognitiva (indiscriminação ao portador do vírus da AIDS); sanção pragmática 2 (qualidade de vida).

- Tema geral de nível discursivo: racismo.

O Percurso Gerativo de Sentido contribui para a identificação de temas, ou seja, é um meio de se conhecer o conteúdo para responder às necessidades de informação demandadas pelos usuários. Essa identificação pode colaborar também para incentivar a leitura e proporcionar o seu acesso.

\section{Considerações finais}

O bibliotecário é responsável por desenvolver os meios de corresponder às necessidades de informação e incentivar a leitura, por isso, deve conhecer o conteúdo dos textos literários.

Pode-se verificar que a literatura de ficção e a leitura são imprescindíveis para garantir um melhor desenvolvimento intelectual, educacional e humano, entre outros fatores, sendo grandes aliadas de crianças e adolescentes. O texto literário infanto-juvenil propicia a leitura de temas que oferecem informações educativas, ao mesmo tempo em que promove o lazer.

Nesse sentido, a análise documental de conteúdo, que utiliza o Percurso Gerativo de Sentido, pode contribuir efetivamente para a identificação dos temas, portanto, colabora também para o 
conhecimento do conteúdo para fins de divulgação dessas obras.

Recomenda-se a partir do estudo realizado que novas pesquisas possam identificar na prática a atuação do bibliotecário escolar, verificando como ocorre o incentivo à leitura e as respostas às necessidades informacionais referentes ao texto literário infanto-juvenil.

\section{Referências}

Alves, R. C. V. (2008). Análise Documental de Textos Literários Infanto-Juvenis: perspectivas metodológicas com vistas à identificação do tema. Marília: Faculdade de Filosofia e Ciências, Universidade Estadual Paulista, 2008. 165 f. Dissertação de Mestrado em Ciência da Informação.

Bandeira, P. (1996). O grande desafio. 2. ed. Ilustrações Rogério Soud. São Paulo: Ática, 1996.

Caldin, C. F. (2003). A função social da leitura da literatura infantil. // Encontros Bibli. 15 ( $1^{\circ} \mathrm{sem} .2003$ ).

Damazo. A. C. (2006). Análise de assunto de conto espírita por meio do percurso figurativo e do percurso temático. Marília: Faculdade de Filosofia e Ciências, Universidade Estadual Paulista, 2006. 126 f. Dissertação de Mestrado em Ciência da Informação.

Dias, E. W.; Naves, M. M. L. (2007). Análise de assunto: teoria e prática. Brasília: Thesaurus, 2007.

Dumont, L. M. M. (2000). Lazer, leitura de romances e imaginário. // Perspectivas em Ciência da Informação. 5:1 (jan./jun. 2000) 117-123. http://www.eci.ufmg.br/ pcionline/index.php/pci/article/view/131/315 (2008-0127).

Fiorin, J. L. (1999). Sendas e veredas da semiótica narrativa e discursiva. // Delta. 15:1 (fev.l jul. 1999). http://www.scielo.br/ (2006-10-28).

Fiorin, J. L. (2008). Elementos de análise do discurso. 14. ed. São Paulo: Contexto, 2008.

Greimas, A. J. (1971). Semántica estructural: investigación metodológica. Versión Española de Alfredo de La Fuente. Madrid: Gredos, 1971. 105-155.

Greimas, A. J. (1975). Sobre o sentido: ensaios semióticos. Tradução de Ana Cristina Cruz Cezar et al. Petrópolis: Vozes, 1975.

Guedes, F. (2001). O livro como tema: história cultura indústria. Portugal: Verbo, 2001.

Lara, L. M. de. (2007). Análise da aplicação do percurso gerativo de sentido em trabalhos de conclusão de curso de biblioteconomia do ano de 2006. Marília: Faculdade de Filosofia e Ciências, Universidade Estadual Paulista, 2007. 174 f. Trabalho de Conclusão do Curso de Biblioteconomia.

Macedo, N. D. de (Org.) (2005). Biblioteca escolar brasileira em debate: da memória profissional a um fórum virtual. São Paulo: Senac São Paulo, 2005.

Magnani, M. do R. M. (2001). Leitura, literatura e escola: sobre a formação do gosto. 2. ed. São Paulo: Martins Fontes, 2001

Moraes, J. B. E. de; Guimarães, J. A. C. (2006). Análisis documental de contenido de textos literarios narrativos: en busca del diálogo entre las concepciones de aboutness/meaning y de recorrido temático/recorrido figurativo. // Scire. Zaragoza: Facultad de Filosofia y Letras da Universidad de Zaragoza. 12 (2006) 120-135.

Moraes, J. B. E. de; Guimarães, J. A. C.; Guarido, M. D. M. (2007). Análisis documental de contenido de textos nar- rativos: bases epistemológicas y perspectivas metodológicas. // García Marco, F. J. (Org.). (2007). Avances y perspectivas en sistemas de información y documentación y en entorno digital. Zaragoza: Prensas Universitarias de Zaragoza, 2007. 93-100.

Pinto Molina, M. (1993). Análisis documental: fundamentos y procedimientos. 2. ed. rev. aum. Madrid: Eudema, 1993.

Polizzi, V. P. (2004). Depois daquela viagem: diário de bordo de uma jovem que aprendeu a viver com AIDS. 19. ed. Ilustração Miadaira. São Paulo: Ática, 2004.

Rey, M. (2006). Diário de Raquel. Ilustrações da capa Laurent Cardon. São Paulo: Cia. das Letras, 2006.

Scheffer, E. M. K. (2002). Fortalecendo elos, transformando cidadãos - as relações entre a biblioteca escolar e a comunidade: um estudo na biblioteca Lourenço Filho em Porto Alegre-RS. // Integrar. 1 (2002). São Paulo: Imprensa Oficial, 2002. 553-572.

Souza, G. P. C. B. de. (2006). A literatura infanto-juvenil brasileira vai muito bem, obrigada! São Paulo: DCL, 2006.

Tatit, L. (2003). Abordagem do texto. // Fiorin, J. L. (Org.) (2003). Introdução à Lingüística: I. objetos teóricos. 2. ed. São Paulo: Contexto, 2003. 187-209. 